Tropical Journal of Pharmaceutical Research, March 2007; 6 (1): 645-651

(C) Pharmacotherapy Group,

Faculty of Pharmacy, University of Benin

Benin City, Nigeria.

All rights reserved.

Research Article

Available online at http://www.tjpr.org

\title{
A Comparative Evaluation of the Flow and Compaction Characteristics of $\alpha$-Cellulose obtained from Waste Paper
}

\section{FO Ohwoavworhua*, TA Adelakun and OO Kunle}

Department of Pharmaceutical Technology and Raw Materials Development, National Institute for Pharmaceutical Research and Development (NIPRD), P. M. B. 21, Abuja, Nigeria.

\begin{abstract}
Purpose: Alpha-cellulose obtained as pulp from fibrous plant materials has found use in the pharmaceutical industry as a disintegrant and direct compression diluent. The aim of this study was to evaluate the suitability of a-cellulose obtained from waste paper as a direct compression excipient.

Method: The flow and compaction characteristics of $\alpha$-cellulose (ACP) obtained from waste paper, in comparison with Avicel PH 101, using the Kawakita and Heckel models were evaluated.

Result: The results indicate that the flow properties of these materials could not be predicted accurately using the Kawakita model. A comparison of compression behaviour and compactibility of the two powders showed Avicel PH 101 to be a slightly better binder. Conclusion: It was concluded that ACP material could find use as a potential dry binder and direct compression diluent in tableting as the binding properties were comparable to those of Avicel PH 101.
\end{abstract}

Keywords: Alpha-cellulose, microcrystalline cellulose, flow and compaction characteristics, direct compression diluent.

*Correspondence E-mail : frankohwo@yahoo.com 


\section{INTRODUCTION}

Cellulose, which is the name generally given to a group of very closely allied substances, is a major constituent of cell wall of most plants and, therefore, provides the backbone structure of plant materials. It is perhaps the most abundant and one of the most useful phytochemical compounds on earth. The cell walls of cotton, pappi on certain fruits and other sources contain some of the purest forms of cellulose; however, because they are cell walls, they enclose varying amounts of other substances that are proteinaceous, waxy and/or fatty. Cellulose in the cell wall of most plants also exists together with encrusting substances, such as lignin, hemicelluloses and pectins. These can be removed by steam under pressure, weak acid or alkali solutions, and sodium sulphite and sulphurous acid ${ }^{1}$.

Plant celluloses, especially those found in wood can be resolved into $\beta$-cellulose, which is soluble in 17.5 per cent sodium hydroxide, and alkali insoluble $\alpha$-cellulose ${ }^{1}$.

Alpha cellulose has been identified in various studies ${ }^{2-5}$ as a potential pharmaceutical excipient which functions as an excellent disintegrant and direct compression diluent in tablet formulations. The continuous search for affordable locally available pharmaceutical raw materials in developing countries led to the evaluation of $\alpha$-cellulose obtained from waste newspaper (ACP), as a potential tablet excipient ${ }^{6}$. Direct compression of powders requires materials exhibiting good flowability, compactibility and compressibility ${ }^{7}$. These properties were evaluated for ACP powder, in comparison with the well-known commercial microcrystalline cellulose, Avicel PH 101, with a view to providing insight into how it will perform in manufacturing a robust tablet form. We have studied these properties using Kawakita ${ }^{8,9}$ and Heckel $^{10,11}$ models.

\section{MATERIALS AND METHODS Materials}

These include Avicel PH101 (FMC Corporation, USA) and ACP powder (particle size $<710 \mu \mathrm{m}$ ) which was obtained as described in an earlier study $^{6}$. All other chemicals used were of analytical or reagent grade.

\section{METHODS \\ Fundamental powder properties}

(a) Microscopy

A Nikon AFX-DX microscope (Nikon Inc.,Japan) was used for preliminary assessment of the nature of the particles in both cellulose materials. Each of the samples was mounted in glycerol and a combination of low and high power objective lenses of $x \quad 100$ and $x 400$ magnification, respectively, were used.

(b) Particle density

The densities of the cellulose powders were determined by the liquid displacement method using xylene as the immersion fluid ${ }^{2}$, and the particle density, $D_{p}$, computed according to the following equation:

$D_{p}=w /[(a+w)-b] \times S G$

where $w$ is the weight of powder, SG is the specific gravity of the solvent, $a$ is the weight of bottle + solvent and $b$ is the weight of bottle + solvent + powder.

(c) Bulk density

The bulk density of each cellulose material at zero pressure (loose density) was determined by pouring a $30 \mathrm{~g}$ quantity of the powder into a 250 $\mathrm{ml}$ measuring cylinder and the volume, $\mathrm{V}_{0}$, determined. The bulk density was calculated as $B_{d}=W / V_{0}$. The results presented are the mean of three replicates determinations ${ }^{2}$.

\section{Flow properties}

Flowability was determined using the Kawakita analysis. $^{8,} 9$ Tapped density was determined using Stampfvolumeter, model STAV 2003 (JEF, Germany) - as a modified Neuman apparatus. ${ }^{12}$ Essentially, the method involved pouring a $30 \mathrm{~g}$ quantity, each of the cellulose materials through an angle $45^{\circ}$ into a $250 \mathrm{ml}$ glass measuring cylinder and the heap of the particles in the cylinder was leveled off horizontally with a thin metallic spatula, and the bulk volume $\left(V_{0}\right)$ was accurately measured. The cylinder was then 


\section{Ohwoavworhua et al}

mechanically tapped and values for the volume of the powder column ( $V$ ) after a separate number of taps $N$ were determined. Three measurements were taken and the constants of this linear equation were calculated separately using tapping numbers below 30 and 10 observation points according to the method of least squares. The behaviour of both cellulose powders in the tapping procedure were compared using numerical constants obtained from the Kawakita plots.

The Kawakita equation for tapping experiment ${ }^{8}$, ${ }^{9}$ which is used for assessing the flow properties of powders is given by:

$$
N / C=N / a+1 / a b \ldots \ldots \ldots \ldots \ldots
$$

Where $a$ and $b$ are constants; $a$ describes the degree of volume reduction at the limit of tapping and is called compactibility; $1 / b$ is considered to be a constant related to cohesion and is called cohesiveness.

$C$, the degree of volume reduction is calculated from the initial volume $V_{0}$ and tapped volume $V$ as:

$$
C=\left(V_{0}-V\right) / V
$$

Numerical values for constants $a$ and $1 / b$ are obtained from the slope, 1/a and the intercept, $1 / a b$, of plots of $N / C$ against number of taps $N$.

\section{Compaction studies}

\section{Preparation of compacts}

Compacts of weights, $300 \mathrm{mg}$, of each of the cellulose materials were made using a single punch power-driven tablet press (Shanghai Tianxiang and Chentai Pharmaceutical Machinery Co. Ltd., China) at machine compression force units from 7 to 13 corresponding to the compression loads of 17.5 to $32.5 \mathrm{kN}$, respectively. Twenty were made at each compression level. Before compression, the die (10.5 mm diameter) and the flat- faced punches were lubricated with a $2 \% \quad \mathrm{w} / \mathrm{v}$ dispersion of magnesium stearate in ethanolether(1:1).The compacts were stored over silica gel for 24hours (to allow for elastic recovery and hardening and prevent falsely low yield values) before evaluations. The dimensions (thickness and diameter) and weight uniformity of ten compacts were determined. The relative density, $D$, was calculated as the ratio of density of the compact, $D_{t}$, to the particle density, $D_{p}$, of the cellulose powder. The data obtained using this 'ejected tablet method' were used to obtain the Heckel plots. Linear regression analysis was carried out over a compression range of 20 to $27.5 \mathrm{kN}$ and parameters from Heckel plots calculated. The area under the Heckel curve (AUHC) was calculated by the trapezoidal method, and used to express the extent of volume reduction (ie, compressibility) that the material had undergone during the entire compression pressure range.

The compaction characteristics of the powders were studied using Heckel equation (Equation 4) 10, 11 .

In 1/1-D $=K P+A$

Where $D$ is the density of the compact relative to the particle density of the material being compacted, $P$ is the applied pressure, $K$ (the slope of the straight line portion) is the reciprocal of the yield pressure, $P y$, of the material. The yield pressure is inversely related to the ability of the material to deform plastically under pressure and $A$ is a function of the original compact volume. From the intercept $A$, the relative density $D_{a}$, can be calculated using the Eq. 5 :

$$
D_{a}=1-e^{-A}
$$

The relative density, $D_{0}$, of the powder at the point when the applied pressure equals zero $\left(D_{0}\right.$ $=$ loose density/particle density) is used to describe the initial rearrangement phase of densification as a result of die filling and high value indicating very dense packing.

The relative density $D_{b}$, describes the phase of arrangement during the initial stages of compression. The extent of this depends on the theoretical point of densification at which particle deformation begins. $D_{b}$ is obtained from the difference between $D_{a}$ and $D_{0}$.

$D_{b}=D_{a}-D_{0} \ldots \ldots \ldots \ldots \ldots \ldots \ldots$ 


\section{RESULTS AND DISCUSSION}

The results of fundamental properties of the cellulose powders are shown in Table 1.

\section{Flow properties}

Plots of N/C versus $\mathrm{N}$ (Kawakita plots) for ACP and Avicel PH101 powders gave the linear relationship shown in Fig 1. Kawakita constants indicate the behaviour of the powder from the bulk density state to the tap density state. The constants of the Kawakita equation were resolved from the slope and intercept of the line from graphs $N / C$ versus $C$ (Table 2). According to published results, small values of constants a (compressibility, or the amount of densification due to tapping) and $1 / b$ (cohesiveness, or how fast or easily the final packing state was achieved) indicate good flowability and small cohesiveness ${ }^{8,13}$. From our results, it was difficult to make comparable conclusions in this regard. ACP densified the least (small compressible value) but attained the final packing state most slowly. On the other hand, Avicel densified considerably but achieved the final packing state rather quickly.

\section{Compaction properties}

Powder compaction is a volume reduction process, and the Heckel equation ${ }^{10}$ is also based on volume change of a powder column during compression. The plots gave a general impression of the densification process of the powder column. The Heckel plots (Fig 2) for both materials were somewhat similar.

To explain the deformation characteristic of $\alpha$ cellulose, Heckel constants as well as area under the Heckel curve, AUHC, were derived from the plots (Table 3 ). The powder column formed by ACP was more densely packed than that formed by Avicel PH 101 in the initial stages of rearrangement as indicated by their $D_{0}$ values (Table 3). The particles of ACP powder are larger, highly composed of spherical- to ovalaggregates with few primary particles which are irregular (Table 1) compared to those of Avicel $\mathrm{PH} 101$ which are small, elongated (fibre-like) and irregular primary particle. These features of the latter could result to formation of bridges and arches, which could in turn prevent close packing of the particles in the bulk state. Thus it seems that the values for the relative density or the packing fraction in the bulk state are strongly dependent on the particle size and shape.

The low $D_{a}$ value for ACP powder is an indication that it opposes the densification process less strongly than Avicel PH 101. Juslin and Paronen ${ }^{14}$ stated that $D_{a}$ describes the share of densification due to contact area between particles; therefore, the low $D_{a}$ value of ACP is an indication of low contact area between the particles. This is expected due to the high population of large spherical- to oval- aggregates present in ACP powder. However, it has been reported that the resultant contact area in a powder bed is dependent upon the interplay of several variables ranging from specific surface area (sequel to particle size), particle size distribution, particle shape to surface properties of the powders such as hardness of the surface. The effect of any of these variables is difficult to distinguish. $^{14}$

$D_{b}$, which describes the phase of rearrangement of particles, the extent of which depends on the theoretical point of densification at which deformation begins, was also determined for the cellulose powders; Avicel PH 101 has a higher value than ACP. ACP particles were more resistant to movement once the initial phase of packing (as a result of die filling) had been completed. This could be attributed to the high cohesive forces likely present as a result of its amorphous nature, being an $\alpha$-cellulose.

The mean yield pressure, $P_{y}$, values were calculated from the slope of the linear line constructed over the compression pressure range (Table 3 ). $P_{y}$ which is inversely related to the ability of the material to deform plastically under pressure, ${ }^{11,14}$ was found to be lower for Avicel PH 101 (Table 3). The results therefore indicate that Avicel PH 101 underwent plastic deformation more easily and rapidly than ACP. This also confirms that ACP is somewhat resistant to deformation. In addition, the lower value of $P_{y}$ (ie larger value of the slope $\mathrm{K}$ ) can be correlated with the crushing strength of tablets; lower values of $P_{y}$ usually indicate harder 
tablets. Such information could be used as means for binder selection when designing tablet formulations ${ }^{15}$. Consequently, ACP with high values of $P_{y}$ (less plastically deformed) might should it be used, in high proportion, as direct compression diluent.

A coefficient of determination $\left(R^{2}\right)$ value close to

Table 1: Fundamental properties of two cellulose powders, ACP and Avicel PH 101

\begin{tabular}{lll}
\hline Properties & \multicolumn{1}{c}{ ACP } & Avicel PH 101 \\
\hline Nature of particles & $\begin{array}{l}\text { Large, highly composed of } \\
\text { spherical- to oval-aggregated } \\
\text { and few primary particles } \\
\text { which are irregular. }\end{array}$ & $\begin{array}{l}\text { Small, less elongated } \\
\text { and irregularly shape } \\
\text { primary particles, } \\
\text { fibre-like, and few } \\
\text { aggregated particles. }\end{array}$ \\
Particle density $(\mathrm{g} / \mathrm{ml})$ & $1.73 \pm 0.06$ & $1.78 \pm 0.12$ \\
Bulk density $(\mathrm{g} / \mathrm{ml})$ & $0.45 \pm 0.0$ & $0.31 \pm 0.04$ \\
\hline
\end{tabular}

Table 2: Parameters from Kawakita plots

\begin{tabular}{lcc}
\hline Characteristics & ACP & Avicel PH 101 \\
\hline Compactibility $a(\%)$ & 19.9 & 29.4 \\
Cohesiveness $1 / b$ & 17.7 & 11.99 \\
\hline
\end{tabular}

Table 3: Parameters derived from density measurements and Heckel plots for ACP and Avicel PH 101

\begin{tabular}{lcccccccc}
\hline \multicolumn{7}{c}{ Parameters } \\
\hline $\begin{array}{l}\text { Cellulose } \\
\text { type }\end{array}$ & $\mathrm{R}^{2}$ & $\begin{array}{c}\mathrm{AUHC} \\
(\mathrm{kN})\end{array}$ & $\mathrm{K}$ & $\mathrm{A}$ & $\begin{array}{c}\mathrm{P}_{\mathrm{y}} \\
(\mathrm{kN})\end{array}$ & $\mathrm{D}_{\mathrm{o}}$ & $\mathrm{D}_{\mathrm{a}}$ & $\mathrm{D}_{\mathrm{b}}$ \\
$\mathrm{ACP}$ & 0.8995 & 12.82 & 0.065 & -0.8258 & 15.4 & 0.260 & -1.284 & -1.54 \\
$\begin{array}{l}\text { Avicel } \mathrm{PH} \\
101\end{array}$ & 0.9393 & 11.61 & 0.074 & -1.1079 & 13.56 & 0.174 & -2.028 & -2.202 \\
\hline
\end{tabular}

$D_{0}=$ Relative density of powder or densification due to die filling

$D_{a}=$ Densification due to die filling and rearrangement

$D_{b}=$ Densification due to rearrangement

require the addition of some plastically deforming components, such as polyvinylpyrrolidone, to reduce structural failure unity is indicative of plastic deformation, whereas decreasing values suggest fragmentation propensity $^{16}$. The $R^{2}$ values obtained over the 
linearity pressure range of the Heckel curves in this study were 0.8995 and 0.9393 for ACP and Avicel PH 101, respectively, suggesting that the former exhibited greater fragmentation. This was, however, expected as ACP existed as aggregates. The results suggest that the consolidation of ACP over the pressure range of linearity may have involved fragmentation of aggregates as well as plastic deformation of the primary particles. For Avicel PH 101 with a larger $\mathrm{R}^{2}$ value, it is explained that plastic deformation of the predominant primary particles contributed

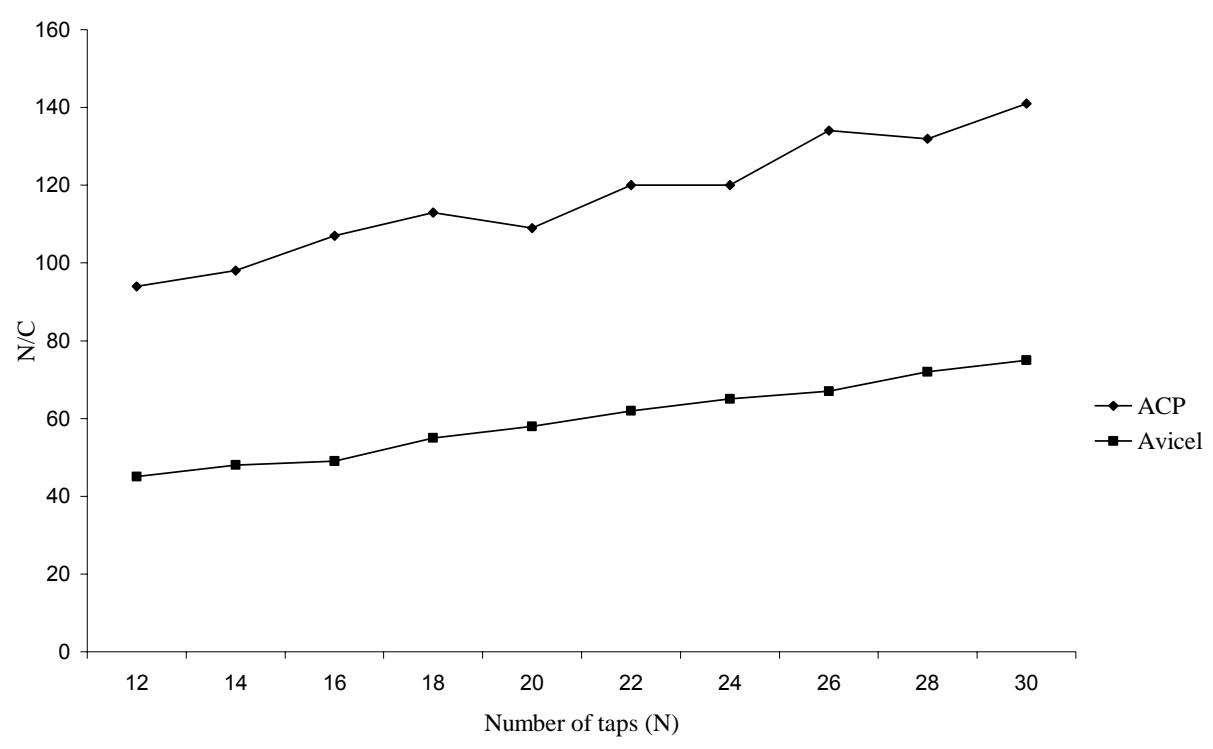

Figure 1: Kawakita plots for two Cellulose powders

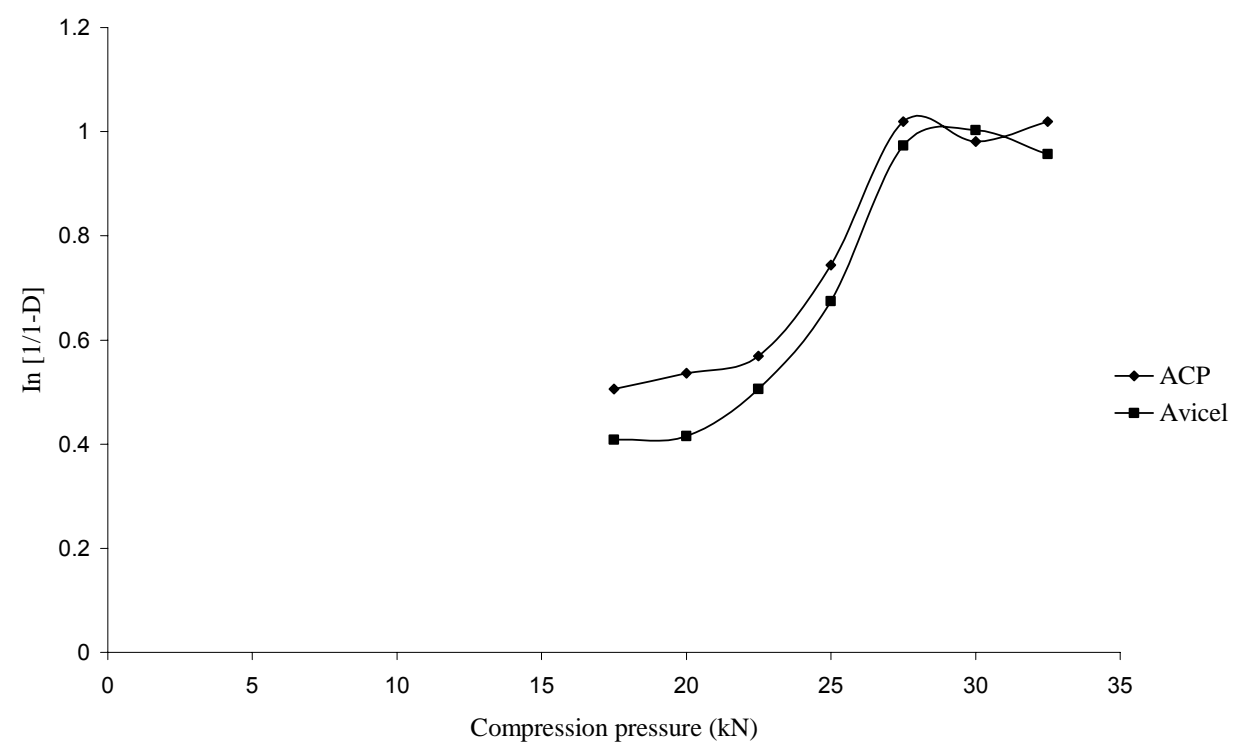

Figure 2: Heckel plots for two cellulose powders 
overwhelmingly to the formation of compacts.

While the mean yield pressure and $R^{2}$ values suggest that Avicel $\mathrm{PH} 101$ was a more ductile material compared to ACP, this deduction could not be made on the basis of the AUHC values (Table 3). Earlier, Kumar et al ${ }^{16}$ had reported that AUHC values could be used to estimate the extent of volume reduction (i.e. compressibility) that a material had undergone during the entire compression range. Larger AUHC was used to predict more plastic flow and low value was interpreted as fragmentation tendency.

\section{CONCLUSION}

While it was difficult to predict the flow properties of the two cellulose powders using the Kawakita model; a comparison of compression behaviour and compactibility of the two powders showed Avicel PH 101 to be a slightly better binder. Nevertheless, it was concluded that ACP material could find use as a potential dry binder and direct compression diluent in tableting.

\section{REFERENCES}

1. Ole G. Carbohydrates or saccharides. In: Charles OW and Ole G (Eds), Textbook of Organic Medicinal and Pharmaceutical Chemistry; J.B Lippincott company, Philadelphia, USA; 1956: pp. 599- 617.

2. Alfa J, Chukwu A, Udeala OK, Nasipuri $R N$ and Wambebe CON. Isolation and physicotechnical properties of grades of cellulose derived from a novel source, Sorghum bicolor. J. Pharmaceut. Res. Dev. (2000): 5 (1):43-49.

3. Okhamafe AO, Igboechi $A$ and Obaseki TO. Celluloses extracted from groundnut shell and rice husk 1 : preliminary physicochemical characterization. Pharm. World J. (1991); 8 (4): 120-130.

4. Okhamafe $A O$ and Azubuike CP. Direct compression studies on low-cost cellulose derived from maize cob. J. Pharm Sci. \& Pharm. Prac. (1994); 1:26-29.
5. Iwuagwu MA, Eba YI, Omokhafe AA and Anozie JD. Locally sourced celluloses as compressed tablet excipients. J. West Afri. Pharm. (1996); 10 (1): 1824.

6. Ohwoavworhua FO, Ogah E and Kunle OO. Preliminary investigation of physicochemical and functional properties of $\alpha$-celluloses obtained from waste paper - a potential pharmaceutical excipient. J. Raw Matr. Res. (2005), 2 (2): 84-93.

7. Shlieout G, Armold $K$ and Muller G. Powder and mechanical properties of microcrystalline cellulose with different degrees of polymerization, AAPS Pharmscitech. 3(2) (2000) article 11.

8. Yamashiro $M$, Yuasa $Y$ and Kawakita $K$. An experimental study on the relationships between compressibility, fluidity and cohesion of powder solids at small tapping numbers. Powder Technology 34, (1983), $225-231$.

9. Kawakita $\mathrm{K}$ and Ludde $\mathrm{KH}$. Some considerations on powder compression equations. Powder Technology, 4 (1970/71), $61-68$.

10. Heckel RW. Density-pressure relationships in powder compaction. Trans Met. Soc. AIME. 221 (1961), 671.

11. Itiola OA. Compressional characteristics of three starches and the mechanical properties of their tablets. Pharm. World J. (1991); 8: 91 - 94.

12. Neuman BS. The flow properties of powders. In: Bean HS, Beckett AH and Carless JE (Eds.). Advances in Pharmaceutical Sciences, Vol. 2. Academic Press, London; 1967, pp. 181 - 221.

13. Pesonen $T$ and Paronen $P$. Evaluation of a new cellulose material as a binding agent for the direct compression of tablets. Drug Dev. Ind. Pharm. (1986): 12, 2091

14. Paronen $P$ and Juslin $M$. Compressional characteristics of four starches. J. Pharm. Pharmacol. 35 (1983), $627-635$.

15. Lachman L, Lieberman HA and Kanig JL (Editors). The Theory and Practice of Industrial Pharmacy $3^{\text {rd }}$ Edition, Lea and Febiger, Philadelphia, 1986, pp 66-99.

16. Kumar V, Kothari SA and Banker GS. Compression, compaction and disintegrant properties of low crystallinity celluloses produced using different agitation rates during their regeneration from phosphoric acid solutions. AAPS PharmSciTech (2001); 2 (2) Article 7. 